\title{
Month-long cardiac surgery boot camp: A proposal to jumpstart resident training
}

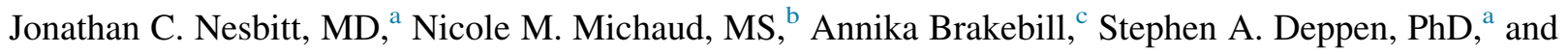
Phillip Williams, BS

\author{
From the ${ }^{a}$ Department of Thoracic Surgery, ' Office of Health Science Education, Programs in Allied Health, \\ Perfusion Institution, and ${ }^{\mathrm{c}}$ Division of Surgical Research, Vanderbilt University Medical Center, Nashville, \\ Tenn. \\ Received for publication Sept 11, 2017; revisions received Feb 27, 2018; accepted for publication March 8, 2018; \\ available ahead of print April 11, 2018 \\ Address for reprints: Jonathan C. Nesbitt, MD, Department of Thoracic Surgery, 609 Oxford House, 131321 st \\ Ave S, Nashville, Tenn 37232 (E-mail: jon.nesbitt@vanderbilt.edu). \\ J Thorac Cardiovasc Surg 2018;156:1151-7 \\ $0022-5223 / \$ 36.00$ \\ Copyright (c) 2018 by The American Association for Thoracic Surgery \\ https://doi.org/10.1016/j.jtcvs.2018.03.048
}

Video clip is available online.

Each academic year, thoracic surgery residency programs receive an influx of eager new resident physicians who arrive with variable exposure to cardiac surgery and inconsistent operating abilities. For residents fresh into their cardiothoracic training, a cardiac operating room can be a daunting and intimidating place. Beginning resident physicians commonly lack familiarity with and understanding of the flow of an operating room or a cardiac operation, and such factors influence trainee involvement and integration in key elements of a procedure until sufficient experience has been achieved. Consequently, training progress can be delayed and protracted.

We developed a month-long, condensed cardiac surgery simulation training program for our entry-level, traditional pathway resident physicians to jumpstart their training. Our goal was to instill sufficiency in fundamental skills to lay a foundation for the years of training ahead. Instead of allowing them to gradually acquire these new skills in the operating room, we taught these skills in an intense boot camp simulation setting in advance of their entry into real operating rooms. We believed that this short, dedicated program would better prepare them to enter their real-time training experiences.

To our knowledge, our cardiac surgery boot camp is the first of its kind to completely remove the trainees from their daily routines for 1 month and commit them to dedicated simulation training before entering the operating room environment. Additional objectives included determining the practicality, feasibility, and value of this condensed program; evaluating the structure and required resources; and demonstrating the ease of replication of this boot camp in similar venues for other programs and specialties.

\section{METHODS}

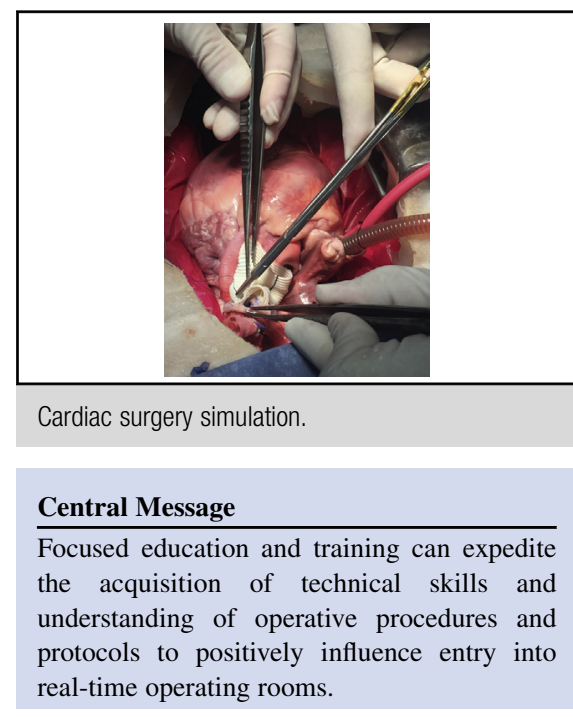

See Editorial Commentary page 1158.

The Vanderbilt University Medical Center (VUMC) Cardiac Surgery Simulation Program began in 2008. Laboratory space was assigned to the program in 2010 to establish a dedicated resource sufficiently equipped and supplied to support training programs associated with cardiothoracic surgery, including cardiopulmonary bypass (CPB) training programs, extracoporeal support (ECMO) training programs, and interactive training sessions with the general surgery residency program. The laboratory has $450 \mathrm{sq} \mathrm{ft}$; is a wet-based laboratory with appropriate mechanical, plumbing, and electrical services; and has the necessary equipment to simulate a surgical setting (lighting, tables, and instrumentation) (Figures 1 and 2 and Video 1). Key additions have been made to enhance the simulation experiences. In 2011, a retired CPB machine was donated to the lab and in 2015 a Califia simulator (Biomed Simulation Inc, San Diego, Calif) was added to enhance CPB and ECMO education. The VUMC Perfusion School also uses the laboratory as a primary resource for training and simulation experiences. The Cardiac Perfusion Technology Program maintains equipment for the pump and simulated CPB and ECMO procedures.

Using the Cardiac Surgery Simulation Curriculum developed by an Agency for Healthcare Research and Quality (AHRQ) study reported by Feins and colleagues, ${ }^{1}$ a 4 -week abridged curriculum with 42 consecutive sessions was created (Table 1). Many of the simulation models used in the AHRQ study were also used for the selected training sessions. The leaders of the cardiac simulation effort at VUMC, in conjunction with the cardiac surgery faculty, met and devised the month-long curriculum with the intent to focus efforts on the most common and essential skills. Two sessions occurred every day, with each session lasting 4 hours.

During August 2016, after arriving to start thoracic surgery residency at VUMC and before beginning any operating room experience, our 2 first-year, traditional pathway thoracic surgery resident physicians 


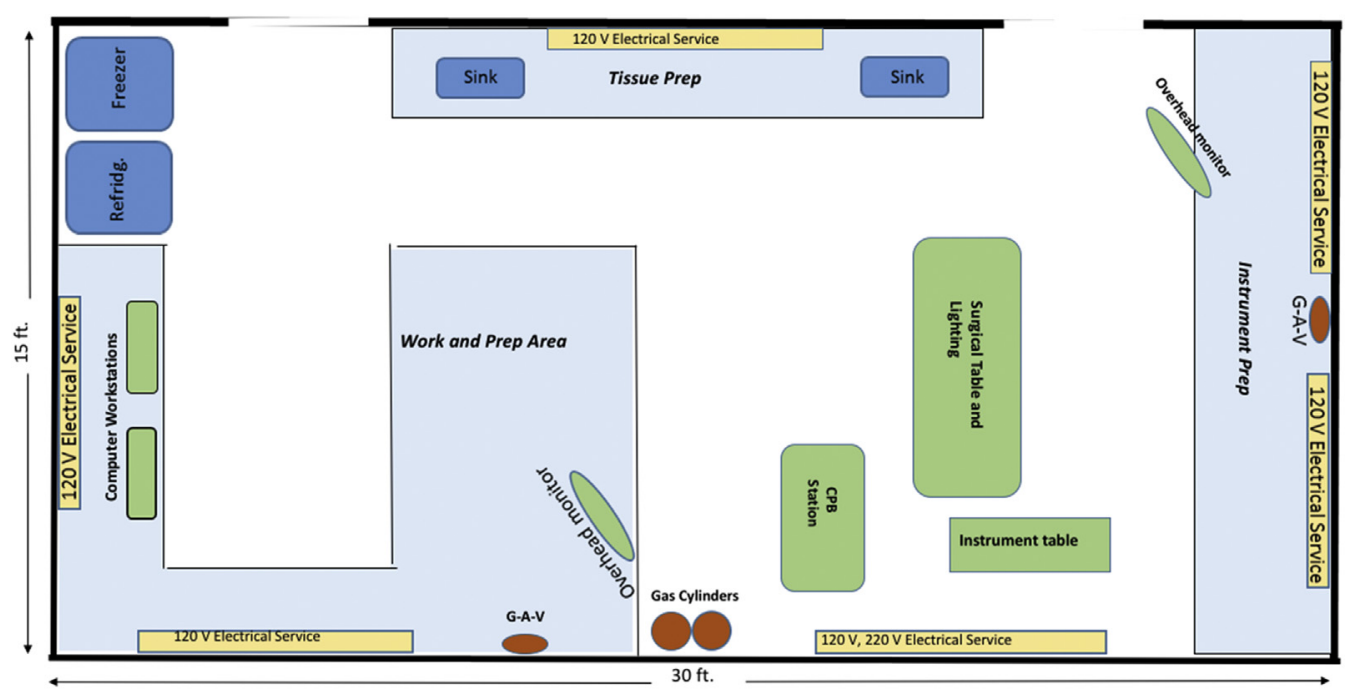

FIGURE 1. Department of Cardiac Surgery Skills and Simulation Laboratory schematic.

participated in our month-long boot camp designed to teach fundamental skills of cardiac surgery. During the first week, the fundamentals of CPB were taught and included focused time in the classroom, with dedicated lectures on CPB physiology and hemodynamic parameters, as well as real-time setup and running of the heart-lung machine. The principles of aortic cannulation (using the aortic cannulation model $^{1}$ ) and atrial cannulation (using a porcine heart) (Animal Technologies Inc, Tyler, Tex) were practiced at length, followed by simulated CPB runs. The next sessions were dedicated to the practice of coronary artery bypass grafting (CABG), both with artificial vein using a Pocket Vessel Anastomosis Trainer (The Chamberlain Group, Great Barrington, Mass) and with Cryovein (CryoLife Inc, Kennesaw, Ga) on porcine hearts. Proximal anastomoses were practiced using porcine aortas. Subsequent sessions were a coalescence of the first sessions. Real-time pump runs were practiced along with $\mathrm{CABG}$, and these sessions continued into week 2 . As each session progressed, certain complexities were added accordingly to the procedures in the form of high-frequency events: air lock, high aortic line pressures, poor cardioplegia delivery, and dysrhythmias. The Califia $\mathrm{CPB}$ simulator was used for most sessions and was attached to a beating heart component during $\mathrm{CPB}$ runs.

For each session, a trained laboratory technician prepared the porcine cardiac tissue blocks. Each heart was prepared by placing balloons in each ventricle as well as perfusion tubing in the vena cavae

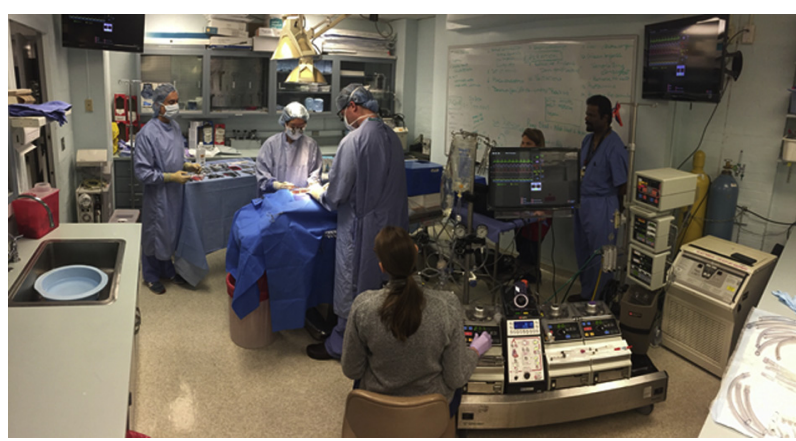

FIGURE 2. Boot camp session using heart-lung machine and cardiopulmonary bypass simulator. and descending aorta. Technical preparation time averaged approximately 30 minutes.

Sufficiency, based on observation and grading by the respective faculty member conducting each session, was established in each endeavor before advancement to the next session. Sufficiency by our standards was derived for the purposes of showing adequacy and acceptability, not competence that comes over time with practice until one reaches a qualified measure of proficiency and completeness. With the brevity of our program and the intention to cover many topics, we did not expect competence, only sufficiency of a skill to allow progression to the next level. Grading was performed using the Likert scale assessment system used by Feins and colleagues. ${ }^{1}$ Sufficiency was considered when grades of at least average to above average were achieved.

During the second week, a day was spent learning and performing median sternotomy and mammary artery dissection on lightly embalmed cadavers. During the third week, 1 full day was used to learn the skills of off-pump coronary artery bypass grafting (OP-CAB) employing a carve-out OP-CAB simulation model. The carve-out OP-CAB model consisted of the standard heart preparation without lungs or the vena cavae cannulae. The preparation was placed in an open container that accommodated attachment of a sternal spreader. A low-flow Masterflex Peristaltic pump (Cole-Palmer Instrument Co, Vernon Hills, Ill) circulated red colored water into the aorta to create coronary flow. A cardiac stabilizer

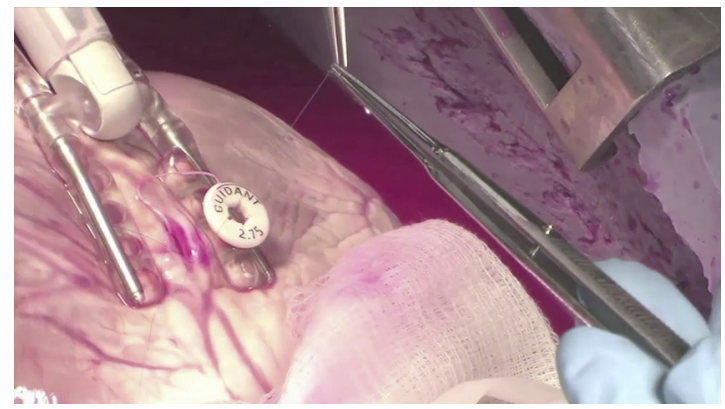

VIDEO 1. Vanderbilt University Medical Center off-pump coronary artery bypass grafting trainer. Video available at: https://www.jtcvs.org/ article/S0022-5223(18)30827-4/fulltext. 
TABLE 1. Vanderbilt University Medical Center cardiac boot camp curriculum, August 2016

\begin{tabular}{|c|c|c|}
\hline & Time & Topic/task \\
\hline \multicolumn{3}{|c|}{ Week 1: Fundamentals of $\mathrm{CPB}$, aortic cannulation, distal CABG, and HFE training } \\
\hline \multirow[t]{2}{*}{ Day 1 (Tues) } & 0800-1200 & Fundamentals of CPB: circuitry and heart-lung machine training \\
\hline & $1300-1700$ & Aortic cannulation on static model \\
\hline \multirow[t]{2}{*}{ Day 2 (Wed) } & 0800-1200 & CABG heart case \\
\hline & $1300-1700$ & Distal anastomosis sewing with Cryovein and static porcine heart trainer* \\
\hline \multirow[t]{3}{*}{ Day 3 (Thur) } & $0800-1000$ & Classroom discussion on the steps of CPB: surgeon/perfusion/anesthesia team \\
\hline & $1000-1200$ & Real-time CPB runs: cannulation, cooling, crossclamping, cardioplegia, warming \\
\hline & $1300-1700$ & Real-time CPB runs: cannulation, cooling, crossclamping, cardioplegia, warming with distal anastomoses \\
\hline \multirow[t]{3}{*}{ Day 4 (Fri) } & 0800-0900 & Classroom discussion on CPB HFE troubleshooting \\
\hline & 0900-1200 & Real-time CPB runs: cannulation, cooling, crossclamping, cardioplegia, warming, distal anastomoses, HFE \\
\hline & $1300-1700$ & $\begin{array}{l}\text { Team communication/real-time CPB runs: cannulation, cooling, crossclamping, cardioplegia, warming, distal } \\
\text { anastomoses, HFE }\end{array}$ \\
\hline \multicolumn{3}{|c|}{ Week 2: Sternotomy, mammary artery dissection, proximal and distal CABG with HFEs } \\
\hline \multirow[t]{2}{*}{ Day 1 (Mon) } & 0800-1200 & Real-time CPB with distal anastomosis sewing \\
\hline & $1300-1700$ & Real-time CPB with distal anastomosis sewing \\
\hline \multirow[t]{2}{*}{ Day 2 (Tues) } & 0800-1200 & Proximal anastomosis sewing on porcine aorta \\
\hline & $1300-1700$ & Real-time CPB with distal and proximal anastomosis sewing, HFE \\
\hline \multirow[t]{2}{*}{ Day 3 (Wed) } & 0800-1200 & Cadaver lab sternotomy and mammary artery dissection \\
\hline & $1300-1700$ & Cadaver lab sternotomy and mammary artery dissection \\
\hline \multirow[t]{2}{*}{ Day 4 (Thur) } & 0800-1200 & Real-time CPB runs: distal and proximal anastomosis sewing \\
\hline & $1300-1700$ & Real-time CPB runs: distal and proximal anastomosis sewing \\
\hline \multirow[t]{2}{*}{ Day 5 (Fri) } & $0800-1200$ & Team communication - Real-time CPB for CABG, HFE \\
\hline & $1300-1700$ & Team communication - Real-time CPB for CABG, HFE \\
\hline \multicolumn{3}{|c|}{ Week 3: OP-CAB, AVR } \\
\hline \multirow[t]{2}{*}{ Day 1 (Mon) } & 0800-1200 & OP-CAB: fundamentals and practice (focused module) \\
\hline & $1300-1700$ & OP-CAB: fundamentals and practice (focused module) \\
\hline \multirow[t]{2}{*}{ Day 2 (Tues) } & 0800-1200 & Real-time OP-CAB with hemodynamic management (conversion to on pump) \\
\hline & $1300-1700$ & Real-time OP-CAB with hemodynamic management (conversion to on pump) \\
\hline \multirow[t]{3}{*}{ Day 3 (Wed) } & 0800-0930 & Classroom discussion: aortic anatomy, aortic valve surgery, de-airing procedures \\
\hline & $1000-1200$ & AVR on porcine task trainer \\
\hline & $1300-1700$ & AVR on porcine task trainer \\
\hline \multirow[t]{2}{*}{ Day 4 (Thur) } & 0800-1200 & Real-time AVR \\
\hline & $1300-1700$ & Real-time AVR \\
\hline \multirow[t]{2}{*}{ Day 5 (Fri) } & $0800-1200$ & Team communication - Real-time AVR \\
\hline & $1300-1700$ & Team communication - Real-time AVR \\
\hline \multicolumn{3}{|c|}{ Week 4: LFE training, MAE, AIAD, SDCF } \\
\hline \multirow[t]{3}{*}{ Day 1 (Mon) } & 0800-1000 & Classroom discussion of MAE \\
\hline & $1000-1200$ & Static model training: MAE \\
\hline & $1300-1700$ & Dry and wet runs of real-time MAE \\
\hline \multirow[t]{2}{*}{ Day 2 (Tues) } & $0800-1200$ & Real-time: CABG, OP-CAB, or AVR with MAE \\
\hline & $1300-1700$ & Real-time: CABG, OP-CAB, or AVR with MAE \\
\hline \multirow[t]{3}{*}{ Day 3 (Wed) } & 0800-1000 & Classroom discussion: AIAD, cerebral protection, grafting techniques \\
\hline & $1030-1200$ & Static model training: management of AIAD \\
\hline & $1300-1700$ & Dry and wet porcine model: AIAD \\
\hline \multirow[t]{2}{*}{ Day 4 (Thur) } & 0800-1200 & Real-time AIAD \\
\hline & $1300-1700$ & Real-time AIAD \\
\hline \multirow[t]{2}{*}{ Day 5 (Fri) } & $0800-1200$ & Team communication: real-time AVR/CABG with an LFE (MAE, AIAD) \\
\hline & $1300-1700$ & Team communication: real-time AVR/CABG with an LFE (MAE, AIAD) \\
\hline
\end{tabular}


TABLE 1. Continued

\begin{tabular}{ccl}
\hline Week 5: SDCF & & \\
Day 1 (Mon) & $0800-1000$ & Classroom discussion of causes and management of SDCF \\
& $1000-1200$ & Walkthrough of emergency action plans during episodes of SDCF \\
& $1300-1700$ & Team communication: real-time AVR/CABG with an LFE (MAE, AIAD, SDCF) \\
Day 2 (Tues) & $0800-1200$ & Team communication: real-time AVR/CABG with an LFE (MAE, AIAD, SDCF) \\
& $1300-1700$ & Team communication: real-time AVR/CABG with an LFE (MAE, AIAD, SDCF) \\
\hline
\end{tabular}

$\overline{C P B}$, Cardiopulmonary bypass; $C A B G$, coronary artery bypass grafting; $H F E$, high-frequency event; $O P-C A B$, off-pump coronary artery bypass; $A V R$, aortic valve replacement; $L F E$, low-frequency event; $M A E$, massive air embolism; $A I A D$, acute intraoperative aortic dissection; $S D C F$, sudden deterioration in cardiac function. *CryoLife Inc, Kennesaw, Ga.

system, donated from the cardiac operating room, was used for cardiac positioning. Cardiac motion was simulated by inflating and deflating the intraventricular balloons at 50 cycles per minute using a large animal Harvard ventilator (Harvard Apparatus, Holliston, Mass). The OP-CAB technical exercise was employed to refine microvascular suturing skills and added another level at which each resident physician's performance was evaluated.

During week 3, aortic valve replacement was taught. Basic anatomy was reviewed, followed by static, then real-time, aortic valve replacement. Weeks 4 and 5 addressed low frequency events that occur while on bypass: air embolism, aortic dissection, failure to wean, and sudden deterioration in cardiac function. During these sessions, communication skills were practiced repeatedly to ensure adequate and effective parlance for a successful procedure. The concluding 2 days allowed the residents to perform procedures to completion and included both high-frequency events and low-frequency events.

Instruments for our simulation lab were previously acquired or purchased, and some instruments were temporarily loaned to the lab by the VUMC cardiac surgery operating room. Selected instruments that were necessary for the boot camp are noted in Table 2. Specific equipment and itemized instruments for each session are the same as noted for the corresponding modules in the Thoracic Surgery Directors Association (TSDA) Cardiac Surgery Simulation Curriculum, found on the TSDA website (www.TSDA.org). Suture material was an essential component

TABLE 2. Cardiac simulation instruments and other boot camp equipment

\begin{tabular}{|c|c|}
\hline Cardiac simulation instruments & Boot camp equipment \\
\hline $\begin{array}{l}\text { Finnochetto retractor (medium size) } \\
\text { Metzenbaum scissors (7-in and 9-in) }\end{array}$ & $\begin{array}{l}\text { Pocket vessel anastomosis } \\
\text { trainer (Chamberlain) }\end{array}$ \\
\hline $\begin{array}{l}\text { Castro needle holders (7-in, } 2 \text { fines: } \\
1 \text { heavy, } 1 \text { locking) }\end{array}$ & $\begin{array}{l}\text { Masterflex peristaltic pump } \\
\quad(1.0 \mathrm{~mL}-25 \mathrm{~L} / \mathrm{min})\end{array}$ \\
\hline DeBakey pick-ups (8-in) & Aortic and venous cannulas \\
\hline Fine pickups (Geralds) & Cardioplegia needle \\
\hline Potts scissors (pinch Potts) & Coronary shunts \\
\hline Reverse Potts scissors (pinch Potts) & Mister/blower \\
\hline Suture scissors & Cardiac stabilizer \\
\hline Regular needle drivers (2 7-in, 2 9-in) & Tubing \\
\hline Aortic crossclamp (angled DeBakey) & Tourniquets \\
\hline Curved DeBakey & Intravenous line bags \\
\hline Aortic punch & Water-soluble paint \\
\hline \multicolumn{2}{|l|}{ Hemostat clamps } \\
\hline \multicolumn{2}{|l|}{ Towel clamps } \\
\hline Tonsil clamp & \\
\hline
\end{tabular}

in the simulation sessions and was acquired mostly through longstanding internal funding. We also collected unused suture in the operating room and were able to acquire some sutures through a donation from our local suture supplier (Ethicon Inc, Somerville, NJ) for the purposes of resident education.

The equipment used for the boot camp is shown in Table 2, with expenses detailed in Table 3. The supplies (intravenous line bags, tubing, cannulas, tourniquets, perfusion tubing, and miscellaneous materials) were mostly obtained as discarded materials from operating rooms and were used repeatedly until exhausted. The anastomosis kits were acquired through the TSDA and The Chamberlain Group. These kits are well designed and are excellent resources for training in microvascular anastomoses. The Masterflex fluid pump was loaned to our lab for the duration of the camp. Expired prosthetic heart valves (St. Jude Medical Inc, St. Paul, Minn, and Edwards Lifesciences Corp, Irvine, Calif) were donated to the simulation lab and were reused multiple times until the valve rings were exhausted. The major expense was the laboratory assistant, whose value to the camp was exceptional and essential. The assistant facilitated setup, model preparation, and take down of each session, allowing the faculty and resident physicians to focus on the tasks of teaching and training. The heart-lung blocks provided real tissue for the sessions and enhanced the experience over synthetic substitutes.

The resident physicians had no direct clinical duties during the boot camp, from 8:00 AM until 5:00 PM each day. They were responsible for night call duties and were integrated into the routine nightly call schedule. The following accommodations in clinical duties allowed the junior resident

\section{TABLE 3. Boot camp expenses}

\begin{tabular}{lc}
\multicolumn{1}{c}{ Item } & Cost \\
\hline Personnel & \\
$\quad$ Research assistant (7 wk, $40 \mathrm{~h} / \mathrm{wk}, \$ 12 / \mathrm{h})$ & $\$ 3360$ \\
Supplies & \\
$\quad$ Balderson blocks (25 blocks, $\$ 55 /$ block) & $\$ 1375$ \\
Instruments (borrowed, owned) & $\mathrm{n} / \mathrm{c}$ \\
Mechanical valves (donated) & $\mathrm{n} / \mathrm{c}$ \\
Suture (donated, collected) & $\mathrm{n} / \mathrm{c}$ \\
Cryovein (purchased, donated)* & $\$ 1000$ \\
Equipment (owned, donated) & $\mathrm{n} / \mathrm{c}$ \\
Disposables and consumables & \\
$\quad$ Gloves & $\$ 175$ \\
$\quad$ Linens & $\$ 80$ \\
Gowns & $\mathrm{n} / \mathrm{c}$ \\
$\quad$ Miscellaneous & $\$ 200$ \\
Total & $\$ 6190$ \\
\hline
\end{tabular}

$n / c$, No cost; that is, donated or discarded operating room surplus. *CryoLife Inc, Kennesaw, Ga. 
physicians to participate in the boot camp. During the simulation program, the VUMC cardiac surgery clinical services, including the operating room and outpatient clinics, were capably staffed by faculty, 4 senior and chief resident physicians, and other allied health personnel. Our cardiovascular intensive care unit, cardiac stepdown, and cardiac regular floor have 24/7 coverage provided by nurse practitioners. The cardiovascular intensive care unit is also managed by full-time cardiac intensivists. Consultations are completed by the oncall resident physician and attending cardiac surgery faculty. The operating room is staffed $24 / 7$ by full-time cardiac surgery first assistants.

The faculty from the Departments of Cardiac and Thoracic Surgery were completely committed to the program, believing that the proposed simulation curriculum could effectively equip our new resident physicians with skills that would provide safe entry into the operating room with immediate participation in cardiac operations. Every faculty member realized the importance of the boot camp and dedicated time to participate in specific sessions. The 2 resident physicians, perfusion faculty, and cardiac surgery faculty attended all simulation sessions.

\section{RESULTS}

Our primary objectives were met by completing the month-long program on schedule and achieving sufficiency in requisite technical skills in cardiac surgery based on faculty assessments. We completed the courses using the outlined curriculum during the first month of residency training, and all tasks were completed as planned with full participation of the cardiac and thoracic surgical faculty. All participants believed the experience was worthwhile and that the effort should be replicated at the beginning of each academic year. At the beginning of boot camp, each resident physician had a low level of experience and understanding of the nuances of CPB and intraoperative cardiac surgery. After this training, they were confident and comfortable with these requisite skills and tasks. At the completion of boot camp, based on past experiences with new resident physicians although there was no objective or comparative assessment, all faculty believed the new resident physicians were much better prepared than previous resident physicians before the boot camp's existence.

We determined the required resources to successfully complete our program along with strategies for acquisition and use of the resources. Although our program was uniquely designed for our training purposes, a similar schedule is applicable to other specialties. With dedication from faculty and committed time for resident physicians, the primary objectives can be accomplished by similar programs.

\section{DISCUSSION}

Surveys from the August 2016 annual TSDA-sponsored boot camp showed that most first-year thoracic surgery resident physicians have limited experiences in cardiac surgery when they begin their training. A pre-boot camp questionnaire was given to the 40 participating junior resident physicians, 31 traditional pathway resident physicians (TPs), and 9 integrated fourth postgraduate year resident physicians. The group of TP resident physicians represented one-third of the total number of TP resident physicians beginning their first year of training in a thoracic surgery training program accredited by the Accreditation Council for Graduate Medical Education. The results from the questionnaire showed that the TP resident physicians had performed very few aortic cannulations, CABG procedures, and CPB setups (Figure 3). The 9 integrated fourth postgraduate year resident physicians had accomplished comparatively more procedures during the first 4 years of their residencies.

The education of thoracic surgery residents remains a challenging, yet rewarding, adventure. Success depends upon many factors, including the training environment, expertise of the mentor, and talents of the trainee. Although training methods in cardiac surgery have evolved under the foundation of apprentice-style tutelage, optimal approaches remain undefined and unclear. In an environment that increasingly stresses optimal clinical outcomes and performance, the balance between resident physician training and patient care is daunting. No clear solutions or substitute training methods have documented success, with the exception of simulation. Dedicated surgical simulation affords the opportunity to learn strategies and practice and refine skills in a controlled, repeatable environment outside of operating rooms, promoting a higher level of function upon entry into operating rooms in real time. During their 3-year, 8-institution AHRQ study, Feins and colleagues ${ }^{1}$ showed the utility of simulation training in cardiac surgery. Overall performance in component tasks and complete cardiac surgical procedures improved during simulation-based training. Furthermore, simulation-based training imparted skill sets for management of adverse events that could help produce safer surgeons. In a review of 113 articles, ${ }^{2}$ simulation was shown to be a reliable tool for assessing learners, effectively teaching procedure skills and teaching topics such as teamwork and communication.

In cardiothoracic training, the role of simulation and its valuable influence has been addressed by many authors over the past 2 decades. $^{3-6}$ In 2007, the Joint Council for Thoracic Surgery Education convened to review trends and concerns in thoracic surgical education. From this meeting, the Council provided thoughtful recommendations, including the need to reform thoracic surgery education, with simulation as a primary focus. ${ }^{7-9}$ The following year, the American Board of Thoracic Surgery added 20 hours of simulation as a training requirement. The extent to which this mandate has been executed or the value of its regular use is unknown. The type, timing, and duration of simulation training have been somewhat arbitrary and have been left to the discretion of each residency program. Consequently, such 


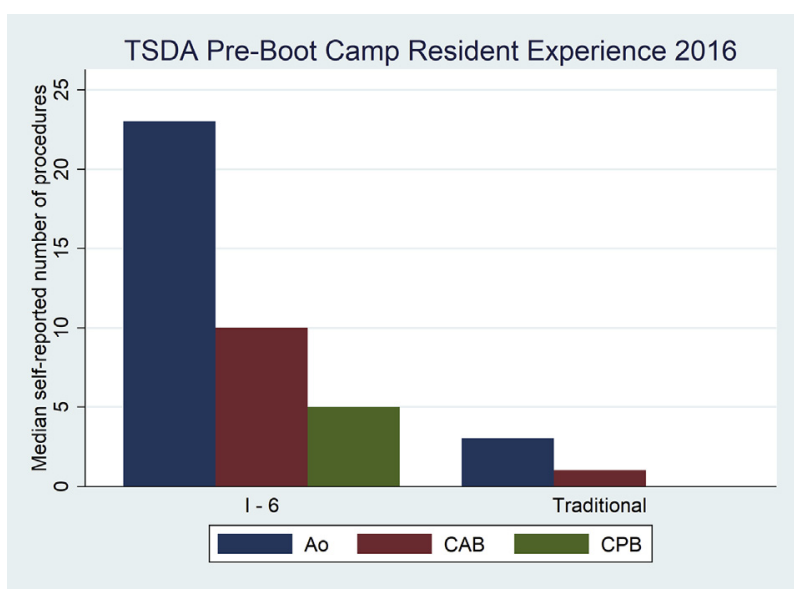

FIGURE 3. Thoracic Surgery Directors Association pre-boot camp resident experience 2016. Median self-reported pre-boot camp experience was for integrated 6-year (I-6) compared with traditional residents with interquartile range (IQR): aortic cannulation (Ao) I-6: 23 (IQR, 17-35) and Ao traditional: 3 (IQR, $0-8)(P<.001)$; coronary ananstomosis $(\mathrm{CAB}) \mathrm{I}-$ 6: 10 (IQR, 3-14) and CAB traditional 1 (IQR, 0-5) $(P=.01)$; and CPB I-6: 5 (IQR, 1-6) and CPB traditional 0 (IQR, 0-5) $(P=.03)$. Wilcoxon test with adjustment for ties was performed. Ao, Aortic cannulation; $C A B$, coronary anastomosis; $C P B$, cardiopulmonary bypass.

training for programs has been fragmented, sporadic, nonsystematic, and-in some circles-viewed as not useful.

As noted by Burkhart and colleagues, ${ }^{3}$ simulation-based $\mathrm{CPB}$ training is an effective technique to build the confidence of thoracic surgery resident physicians regarding knowledge and applications. ${ }^{3}$ Scenario-based practice in a specifically designed simulated environment is a valuable adjunct to traditional educational methods and has the potential to improve the training of thoracic surgery resident physicians. In their review article on simulation in cardiothoracic surgery training, Trehan and colleagues $^{5}$ expressed that cardiothoracic surgery training can benefit greatly from simulation, considering the high risks and broad range of open, minimally invasive, and endovascular techniques that trainees are expected to learn.

Teaching, training, and learning new skills are optimally conducted in a controlled environment in which instruction, practice, and feedback can be consistently provided and replicated. In our simulation program, dedicated sessions for learning and for repetitive skills practice provided the opportunity for each resident physician to obtain knowledge, confidence, and a degree of competence that otherwise could take many months to obtain in the traditional method. Furthermore, we designed the curriculum and each session to allow the direct oversight and supervision of the faculty, ensuring that we provided the intended information and proper skills instruction, instead of expecting the resident physician to do the same on his own time.
The first month of residency was chosen to conduct our program because we believed the resident physicians were entering their residency with limited skills and relatively few biases in cardiac surgery. This provided our faculty with an impressionable time to optimally instruct new skills. The simulated learning environment allowed the faculty to control each session, ensuring that the residents had exposure to the topics and training as intended. We subscribe to the theory that 20 hours of concentrated, intelligent, focused effort allows one to learn basic and fundamental skills, with sufficiency as the goal. ${ }^{10}$ Once sufficiency at a skill is acquired, training and learning with deliberate and systematic practice over time generate expertise. Our 1-month program therefore allowed at least 20 hours of effort for each skill, with our belief that sufficient competence could be achieved in each key skill during this time.

Key to the success of the program was the involvement and commitment of the faculty. A cardiac or general thoracic surgery faculty member, all of whom were involved during the month-long program, proctored each session. The interaction and engagement of each member directly influence the level of training and realism that was brought into each session by voices, operative sounds, and operative urgency directed by the proctor. Standard commands and communication skills between the surgeon, anesthesiologist, perfusionist, and scrub technicians were practiced throughout all scenarios. Direct instruction with procedural repetition provided the needed venue for sufficient skills to be achieved. An additional benefit noted by the resident physicians was the positive influence of dedicated faculty participation on the resident-faculty relationships.

The decision to consider then implement the boot camp occurred with the agreement of all core cardiac and thoracic faculty. Several months before the start of boot camp, the faculty met and discussed the program and decided to move forward based on published data, perceived merit, and overall value. Most faculty members had been involved with VUMC cardiac simulation events during prior years, were familiar with the composite trainers, and had positive experiences with prior residents. Every faculty member participated in 1 or more sessions. No educational or salary rewards were given, but participation was noted in year-end faculty evaluations. Certain expectations occur with all teaching faculty, in all residency programs, and include participation in journal club, weekly curricular activities and teaching conferences, quality improvement meetings, specialty conferences, research endeavors, perioperative case discussions and grading, and milestones evaluations, to name just a few. Carving out several hours for 1 month was not burdensome and was actually enjoyed by faculty because of the type of teaching in a low-key environment. And the faculty-resident relationship was enhanced. 
Another critical element of our successful completion of the program was the allocation and commitment of time for the resident physicians to participate in the course. Each resident physician had uninterrupted time to learn and to practice without the interference of outside obligations. Clinical duties were suspended during the daytime hours and were managed by faculty, senior resident physicians, and allied health personnel. The time in the program was identical to a resident physician spending the day in an operating room, perhaps doing 2 4-hour cases, and then taking routine night call as deemed by the call schedule. The overall time in the boot camp fell well within the 80-hour workweek.

Questions remain regarding how to most effectively use simulation, when to use simulation, what platforms are best, what methodologies are optimal, and who will teach. Although we had the advantage of a perfusion simulator and a heart-lung machine, realistic simulation sessions can be easily accomplished without these adjuncts. The technical components of the various operations can be performed using simple models designed to focus on the task at hand. Porcine tissues are available for commercial purchase. Disposable equipment and sutures that would otherwise be discarded can be salvaged from operating rooms. Several options are available for suture acquisition, as we demonstrated, including local collection of expired or unused sutures, an educational grant from a suture company, local suture supplier support of resident education, purchase through the hospital using discounted volume contract pricing, or direct purchase from a suture company (most expensive option). Finally, selected instruments can be purchased or even loaned to the simulation effort from associated institutional resources.

The primary limitation with our program was the fact that we had only 2 participants. One can argue that the amount of time and effort was considerable. We claim that, like many things, the high investment in our residents was well worth the time and that both residents and faculty benefited from the efforts.

\section{CONCLUSIONS}

A dedicated cardiac surgery boot camp using composite task trainers can provide a valuable experience for both resident physicians in the initial phases of their training and for faculty who engage in each of the educational experiences. Such a program can be successfully accomplished with dedicated faculty and affordable resources. High-fidelity simulation enhances the level of operating room imitation, which influences the overall quality of realism for each experience. Residency programs should consider similar types of opportunities for their resident physicians at the beginning of residency to jumpstart training. A short period of focused education and training can expedite the acquisition of technical skills and understanding of operative procedures and protocols to positively influence entry into real-time operating rooms.

\section{Conflict of Interest Statement}

Authors have nothing to disclose with regard to commercial support.

The authors thank the boot camp faculty: T. Absi, S. A. Ball, B. R. Barton, C. Choi, M. R. Danter, E. A. Gillaspie, E. L. Grogan, C. A. Kaiser, B. A. Mettler, W. H. Merrill, M. R. Petracek, and A. S. Shah. Ethicon, Inc, donated suture material; Cryolife, Inc, donated saphenous vein.

\section{References}

1. Feins RH, Burkhart HM, Conte JV, Coore DN, Fann JI, Hicks GL, et al. Simulation-based training in cardiac surgery. Ann Thorac Surg. 2017;103: 312-21.

2. Okuda Y, Bryson EO, DeMaria S Jr, Jacobson L, Quinones J, Shen B, et al. The utility of simulation in medical education: what is the evidence? Mt Sinai J Med. 2009; 76:330-43.

3. Burkhart HM, Riley JB, Hendrickson SE, Glenn GF, Lynch JJ, Arnold JJ, et al The successful application of simulation-based training in thoracic surgery residency. J Thorac Cardiovasc Surg. 2010;139:707-12.

4. Fann JI, Calhoon JH, Carpenter AJ, Merrill WH, Brown JW, Poston RS, et al. Simulation in coronary artery anastomosis early in cardiothoracic surgical residency training: the boot camp experience. J Thorac Cardiovasc Surg. 2010;139:1275-81

5. Trehan K, Kemp CD, Yang SC. Simulation in cardiothoracic surgical training: where do we stand? J Thorac Cardiovasc Surg. 2014;147:18-24.e12.

6. Bruppacher HR, Alam SK, LeBlanc VR, Latter D, Naik VN, Savoldelli GL, et al. Simulation-based training improves physicians' performance in patient care in high-stakes clinical setting of cardiac surgery. Anesthesiology. 2010;112:985-92.

7. Chitwood WR Jr, Spray TL, Feins RH, Mack MJ. Mission critical: thoracic surgery education reform. J Thorac Cardiovasc Surg. 2008;136:812-3.

8. Feins RH. Expert commentary: cardiothoracic surgical simulation. J Thorac Cardiovasc Surg. 2008;135:485-6.

9. Carpenter AJ, Yang SC, Uhlig PN, Colson YL. Envisioning simulation in the future of thoracic surgical education. J Thorac Cardiovasc Surg. 2008;135: 477-84.

10. Kaufman J. The First 20 Hours: How to Learn Anything-Fast. New York: Portfolio/Penguin; 2013. 